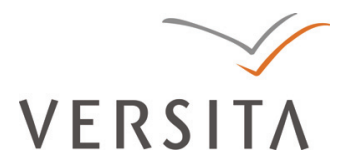

Folia Oeconomica Stetinensia

DOI: $10.2478 / \mathrm{v} 10031-012-0008-7$

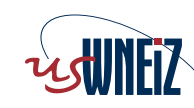

Wydzial Nauk Ekonomicznych i Zarządzania

Uniwersytetu Szczecińskiego

\title{
MODELING THE REAL ESTATE PRICES IN OLSZTYN \\ UNDER INSTABILITY CONDITIONS
}

\author{
Mirosław Bełej, Ph.D. \\ University of Warmia and Mazury in Olsztyn \\ The Faculty of Geodesy and Land Management \\ Department of Land Management and Regional Development \\ Prawocheńskiego 15, 10-720 Olsztyn, Poland \\ e-mail: caprio@uwm.edu.pl
}

Sławomir Kulesza, Ph.D.

University of Warmia and Mazury in Olsztyn

Faculty of Mathematics and Informatics

Chair of Relativistic Physics

Stoneczna 54, 10-710 Olsztyn, Poland

e-mail: kulesza@matman.uwm.edu.pl

Received 13 July 2012, Accepted 20 November 2012

\begin{abstract}
The paper deals with the description of the issues related to the dynamics of the real estate market in terms of sharp, unexpected changes in the housing prices which have been observed in the last decade in many European countries due to some macroeconomic circumstances. When such perturbations appear, the real estate market is said to be structurally unstable, since even a small variation in the control parameters might result in a large, structural change in the state of the whole system.

The essential problem addressed in the paper is the need to define and discriminate between the intervals of stable and unstable real estate market development with special attention paid to the latter. The research aims at modeling hardly explored field of discontinuous changes in the real estate market in order to reveal the bifurcation edge. Assuming that the periods of sudden price changes reflect an intrinsic property of the real estate market, it is shown that the evolution path draws for most of the time a smooth curve onto the stability area of the equilibrium surface, and only briefly penetrates into the instability area to hop to another equilibrium state.
\end{abstract}

Keywords: real estate market, catastrophe theory, system dynamics.

JEL classification: C51, R31, R32. 


\section{Introduction}

The development of the real estate market is closely connected with economic and social development. It is also both a cause and effect of many social and economic phenomena ${ }^{1}$. Its influence on the economic situation is especially visible in Eastern European countries which had to transform their economic systems in order to comply with the requirements of the free market economy.

In Poland the real estate prices rose steadily between 1990 and 2000, subject to periodic variations. Such a trend and its length and stability pointed to a certain security and stabilization. It was not until 2004 (when Poland entered the European Union, which, in turn, resulted in easy access to low-cost capital) that the real estate prices started to fluctuate rapidly - such a situation was especially visible from 2006 to 2007 and undermined the belief in real estate market stability. The recent real estate market dynamics and the accompanying changes in the real estate prices were very intense, multi-phased and, in some periods, could be interpreted as market instability.

The authors believe that the conventional methods of real estate market price analysis (multiple regression ${ }^{2}$, geographically weighted regression ${ }^{3}$, theory of rough sets ${ }^{4}$, artificial neural networks ${ }^{5}$, logit models ${ }^{6}$ or the creation of real estate price indices ${ }^{7}$ ) are very useful during the periods of stable market development, while during periods of instability such methods are insufficient. It means that defining and re-evaluating the meaning of periods of stable and unstable real estate market development and the quest for a new language for description and analysis that is adequate for such different phases of real estate market development constitutes a very important research question.

The authors believe that the strong fluctuations in the real estate prices observed in many countries (including Poland) are not just disruptions of trends or cycles but are an essential part of the market, which - destabilized by changes in the macroeconomic situation - seeks a new state of equilibrium through quasi-discrete changes in prices. It means that real estate market instability can generate a fluctuating, discontinuous change in real estate prices. The real estate market is a dynamic system in which periods of sudden fluctuations in prices can be defined as critical moments in its evolution. In such moments, the ability to develop further inside the current model is exhausted and a search for a new, alternative path of development commences.

This article offers and verifies the possibility to apply mathematical models from catastrophe theory to the real estate market. Such models allow analyzing long-term trends in 
real estate prices, both in the stable and unstable periods while using only one mathematical theory. The problem of stability analysis of either price or other economic measures (stock market indices, for example) appears to be highly non-linear. In such a case, other non-linear approaches, including Markov switching processes, bubble tests, and chaos theory ${ }^{8}$, can be applicable as well.

\section{Research methodology - the catastrophe theory}

The catastrophe theory, also known as the morphogenesis theory, was first introduced in 1971 by the French mathematician Rene Thom ${ }^{9}$. The theory considers dynamical systems described by $\mathrm{n}$-dimensional state variable and k-dimensional control parameter exhibiting the so-called discontinuous transitions during their evolution. Such systems can be thought of as being immersed in $n$-dimensional phase space while their evolution path tracks a curve driven by a k-dimensional potential vector field. The vector field is called potential if and only if a scalar function (potential) exists such that its negative gradient equals to this vector field. All the roots of the gradient of the potential function form a set referred to as the system equilibrium surface. Assuming that the system is subjected to quasi-static processes, i.e. it remains near the equilibrium throughout its evolution, the evolution path draws a smooth curve right onto or near the equilibrium surface. Apart from that, however, there are also critical points on the equilibrium surface, at which small but continuous changes in control parameters give rise to discontinuous change in the system state, called discrete transition, phase-transition or catastrophe. The catastrophe theory distinguishes seven elementary transitions of this type depending on the number of state variables and control parameters. The catastrophes in a 1-dimensional state space are depicted as cuspoids (in brackets number of control parameters are given): fold (1), cusp (2), swallowtail (3), and butterfly (4), whereas the catastrophes in a 2-dimensional state space are depicted as umbilics: hyperbolic (3), elliptic (3) and parabolic (4). The elementary catastrophes are named after characteristic shapes of their equilibrium surfaces.

What is the importance of elementary catastrophes for the evolution of the real estate market? Firstly, the catastrophe theory stresses the structure of relations between independent variables giving rise to the abovementioned potential vector field, which influence the system state in a highly non-linear manner. Thus, small changes within control parameters may lead to significant (structural) changes in the overall system. In classical statistical methods such as regression analysis, the structural relations between variables are often treated as noise perturbing long-term, stable trends. Secondly, the real estate market evolves with time being influenced by 
several factors. The catastrophe theory gives helpful tool for estimating the quantitative effect of given variables and their combinations on the system behavior.

The paper presents results of numerical analysis of the dynamics of housing prices in terms of the cusp catastrophe model parametrized by: asymmetry factor $\alpha$, bifurcation factor $\beta$, and single state variable $y$. Potential function $V$ is then given as:

$$
V(y, \alpha, \beta)=\frac{1}{4} y^{4}+\frac{1}{2} \beta y^{2}+\alpha y
$$

The equilibrium surface is formed by the roots of the partial derivative of the potential with respect to the state variable $y$ :

$$
V_{E Q}(y, \alpha, \beta)=y^{3}+\beta y+\alpha
$$

Equation follows from the definition of an equilibrium state in which the isolated system does not change with time.

In order to study the effect of several independent observables the control space need to be extended, but the number of control parameters is limited depending on the catastrophe model. Montagnana et al. ${ }^{10}$ overcame this problem by using multivariable control space (umbilic catastrophe models), even though such an approach made the fit procedure sophisticated. Unlike Montagnana et al., the solution presented here makes use of canonical variables introduced into the cusp model (2-dimensional control space), so that the simplicity of the numerical fit procedure combines with the variety of the parameters that can be introduced simultaneously. Canonical variables are the linear (weighted) combinations of the independent variables in the form:

$$
\begin{aligned}
& \alpha=\alpha_{0}+\sum_{i=1}^{n} \alpha_{i} x_{i} \\
& \beta=\beta_{0}+\sum_{i=1}^{n} \beta_{i} x_{i}
\end{aligned}
$$

Several independent variables were joined together to form the asymmetry factor and bifurcation factor, and then these canonical variables were analyzed to obtain the best possible fit.

Previous considerations are generally applicable to quasistatic processes in isolated systems, whereas the real estate market is actually an partly-open system influenced by a large variety of time-dependent factors. This makes the problem difficult, because the same configuration of control parameters might give rise to different system behavior depending on the stage of the evolution. 
To get the best possible numerical fit, the 'cusp' package for R software environment was used. The package implements and extends the method of Cobb and Watson ${ }^{11}$ to quantitatively fit several independent observables to the cusp catastrophe model in a statistically principled way ${ }^{12}$.

\section{Data description}

According to the catastrophe theory methodology, in order to construct a model of price change we have to define the variable $y$ and the control variables $\alpha$ and $\beta$. The control variables (asymmetry and bifurcation coefficients) are accordingly selected as line combinations of many independent parameters whose changes define the actual state of the system investigated. This means that we have to choose the so-called "determinants" of real estate market development whose changes in time are strongly correlated with a change in the variable that characterizes the real estate market situation.

The research into the causes of fluctuations in the real estate market in Poland usually analyze the following parameters ${ }^{13}$ : gross domestic product (GDP), the rate of registered unemployment, the changes in employment, household income, demographic conditions, the number of new dwellings, interest rates, mortgage value, costs per square meter of floor area. The authors ${ }^{14}$ have analyzed the choice of an appropriate set and the number of control parameters as well as the reasons behind using the cusp model, and realize the importance of this question and that it requires verification of some parameters and construction of a variety of models. These problems will be addressed in the subsequent research. This article uses the set of parameters shown in the Table 1 for constructing the variables $\alpha$ and $\beta$.

Table 1. Parameters used for constructing control variables $\alpha$ and $\beta$ in the cusp model

\begin{tabular}{|c|c|c|}
\hline No. & Abbreviated name & Parameter \\
\hline 1. & GDP & Gross domestic product \\
\hline 2. & UNMPL & Unemployment rate \\
\hline 3. & AVPR & Average interest rate of the national bank \\
\hline 4. & INFL & Inflation rate \\
\hline 5. & NNDWEL & Number of new dwellings \\
\hline 6. & NTRANS & Number of transactions \\
\hline
\end{tabular}

Source: own study.

The parameters GDP, UNMPL, INFL and NNDWEL were acquired from the General Statistics Office; AVPR is an average of the reference and lombard interest rates of the National 
Bank of Poland while NTRANS was established during the authors' own research on the basis of the existing real estate price database.

The features of the real estate market were the reason for choosing only one factor for the variable $y$ - the average monthly price per square meter of residential floor area. The Register of Prices and Values maintained by the City Administration Office in Olsztyn was the source of data representing around 5,600 residential real estate sale transactions (dwellings). The time perspective within which the trends in changes of real estate prices were analyzed covered the period from May 2003 until December 2010.

Figure 1 shows the relation between the gross domestic product (GDP) and the unemployment rate (UNMPL) to the average price per square meter of the analyzed real estate. There were three periods of fluctuations of prices from 2003 to 2010. The first two (2003-2006 and 2008-2010) can be defined according to the catastrophe theory as stability periods. The real estate prices, notwithstanding some fluctuation, grew at the rate of ca. $20 \%$ per year in the first period and in the second period they fell at the rate of ca. 10\% per year. In 2007 (and partially also in the last months of 2006) a sudden growth in real estate prices could be noted - ca. $100 \%$ per year, which can be defined as an instability period. The authors believe that this period was a time of a sudden quality change in the real estate market which took the form of a discontinuous change in real estate prices influenced by a small but steady change in the control parameters. The previous course of real estate price development (2003-2006) could not be continued anymore and a new one (2008-2010) was created by a catastrophe (2007).
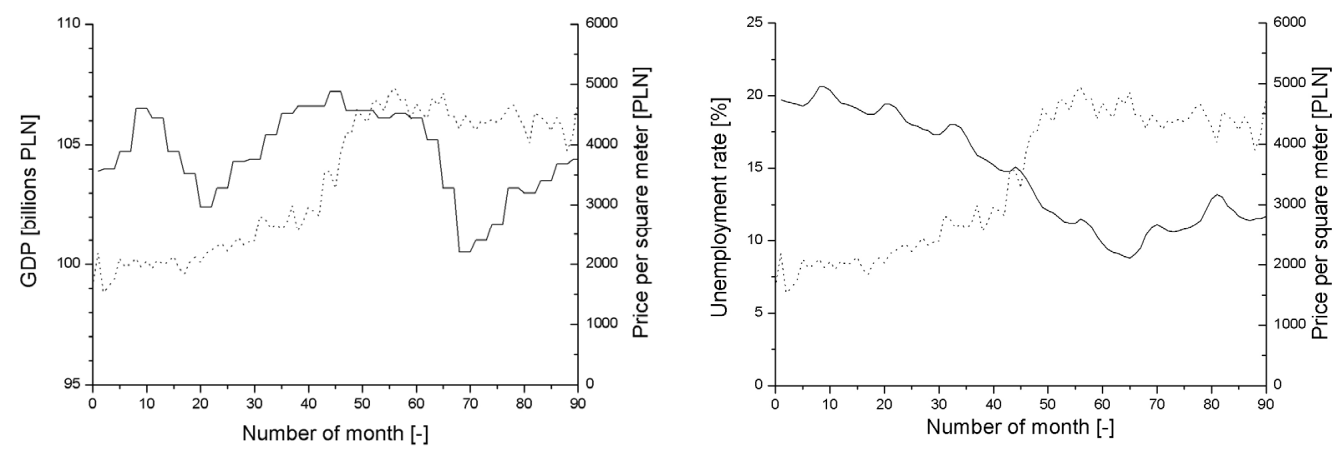

Fig. 1. The gross domestic product (GDP) and the unemployment rate (UNMPL) (solid lines in both figures) in relation to the average price per square meter of the real estate analyzed (dashed line in both figures)

Source: own study. 
The main reason to apply the cusp model in the catastrophe theory is the so-called multimodality of empirical data. According to Jakimowicz ${ }^{15}$, multi-modality means that a system has more than one equilibrium state. In such case, the potential function $\mathrm{V}$ has to have at least two minima. In order to verify this an empirical spread of the real estate prices was constructed for the period 2003-2010 (Figure 2).
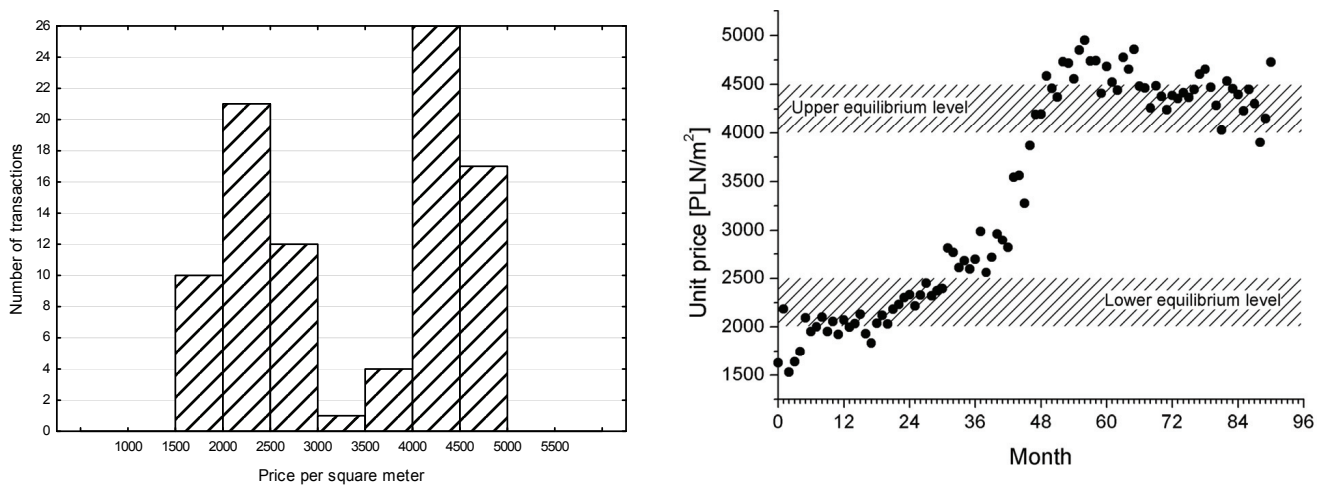

Fig. 2. (Left) A histogram showing the transaction prices per square meter of residential real estate between June 2003 and December 2010. (Right) A scatter plot of transaction prices within the analyzed interval with suggested equilibrium levels

Source: own study.

The analyzed spread of real estate prices is multi-modal, which results in a double peak histogram with two distinct price maximums (2000-2500 PLN and 4000-4500 PLN). In such case, a classical statistical interpretation suggests that the sample is not heterogeneous and the observations might come from two distinct populations with a distribution close to normal. However, since only one population was analyzed in the case considered, it might serve as proof that the price change can be divided into two different periods of real estate market stability and one period of real estate market instability. Two price maximums might be equaled with two market equilibriums, which might prove the bimodality of the potential function $V$. A sudden decrease in the number of transactions during the change in prices might mean that the system evolution path goes through so-called "zones of inaccessibility" - points of the unstable equilibrium of the system. 


\section{Testing cusp model}

Empirical data taken from the real estate market in Olsztyn between 2003 and 2010 have been processed numerically to obtain the best fit to the cusp catastrophe model, as it is summarized in Table 2. To assess the validity of the model an additional comparison was made between the cusp model and both linear and logistic models using several measures of the fit quality, namely: pseudo- $\mathrm{R}^{2}$, likelihood ratio (log-Lik), Akaike Information Criterion (AIC), and Bayesian Information Criterion (BIC).

The pseudo- $\mathrm{R}^{2}$ parameter is estimated according to formula proposed by $\mathrm{Cobb}^{16}$ :

$$
R^{2}=1-\frac{\operatorname{Var}(\Delta)}{\operatorname{Var}(y)}
$$

where $\operatorname{Var}(\Delta)$ is the error variance defined as the variance of the differences between the measured values and the mode of the distribution that is closest to this value, while $\operatorname{Var}(y)$ is the variance of the state variable. Note, however, that this measure is something of an oddity, as it can be either positive or negative unlike the coefficient of determination $\mathrm{R}^{2}$. In contrast to ordinary regression methods, having a set of values of the observables the cusp model may predict multiple values for the state variable. The point is, however, that ordinary regression methods associated with unimodal probability distributions result in estimates that asymptotically converge to the mean values (weighted center of the distribution), whereas in the cusp model the distribution becomes bimodal for certain control parameters, hence the mean value lies somewhere in-between the modes (inside the repeller area). Such a result is contradictory to the idea of the mean value, because the estimated value is relatively unlikely to be observed. Thus, if the distribution is strongly skewed, i.e. the error variance (deviation from the mode) is larger than the variance of the state variable (deviation from the mean), the negative pseudo- $\mathrm{R}^{2}$ is allowed.

Apart from the pseudo- $\mathrm{R}^{2}$ measure, the presence of a cusp catastrophe can be deduced from additional statistics. On the one hand, the likelihood ratio should be significantly higher than that of the linear regression model. On the other hand, Hartelman ${ }^{17}$ suggested comparing the cusp model with the non-linear fit to the logistic curve. The logistic function is chosen due to its similarity to sudden transitions of the cusp: it does not possess critical points, but instead it draws arbitrarily steep curve as a function of small changes in an independent variable. Unfortunately, both models are not nested, and hence the fit cannot be assessed directly on the basis of the likelihood ratio. To this end, both AIC and BIC indices are more appropriate, and their lower values indicate a better fit. 
Table 2. Summary of the fit quality measures for analyzed models: linear, logistic and cusp

\begin{tabular}{|l|r|r|r|r|}
\hline \multicolumn{1}{|c|}{ Model } & \multicolumn{1}{c|}{$\mathrm{R}^{2}$} & \multicolumn{1}{c|}{ logLik } & \multicolumn{1}{c|}{ AIC } & \multicolumn{1}{c|}{ BIC } \\
\hline Linear model & 0.9455 & -636.0376 & 1288.0752 & 1308.1621 \\
\hline Logistic model & 0.9765 & -597.7034 & 1225.4067 & 1263.0696 \\
\hline Cusp model & 0.9728 & 34.7321 & -37.4642 & 2.7095 \\
\hline
\end{tabular}

Source: own study.

In the light of the above guidelines, all the statistical measures indicate the predominance of the cusp model over the linear and logistic models, even though the pseudo- $\mathrm{R}^{2}$ is larger for the logistic model $(0,9765)$ than for the cusp model $(0,9728)$. As such, however, the pseudo- $\mathrm{R}^{2}$ is not reliable for the fit assessment, especially when the probability distribution is asymmetric.

The evolution path of the system over the equilibrium surface of the cusp model is shown in Figure 3, in the form of a 3-dimensional plot in the phase space, and its 2-dimensional projection onto the control plane. Both plots can be useful to decide whether or not any discontinuous transition occurs, and the circumstances (control parameters) under which it takes place. Closed circles correspond to the state variable, namely the mean housing price per square meter. As seen in Figure 3, the state variable initially tracks a smooth curve within the stability area, but once the fold is approached, the curve sharply moves upwards. The shadow in Figure 3 marks the instability area with solid lines referred to as the bifurcation (instability) edge. The transition occurs when the path temporarily enters the instability area close to the tip which is followed by
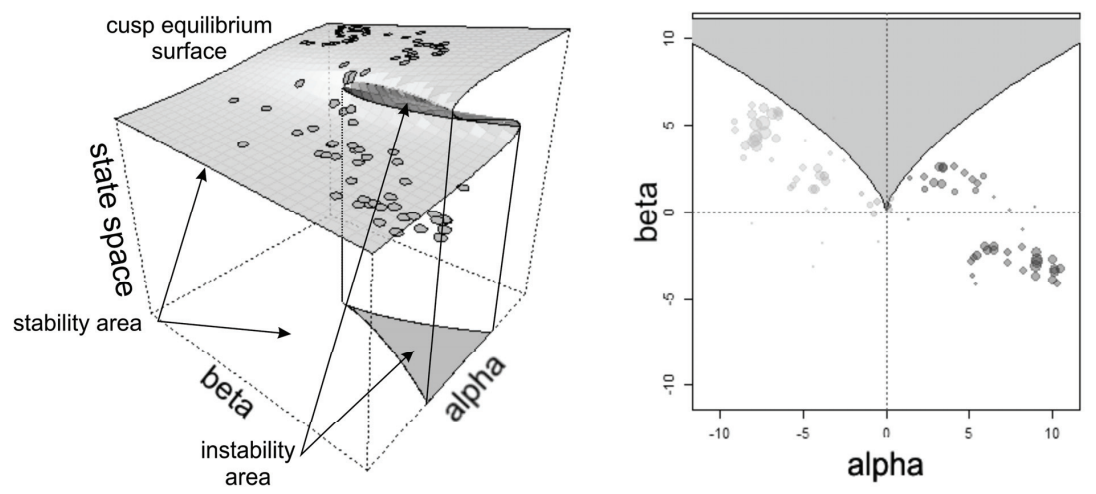

Fig. 3. A 3-dimensional plot of the evolution path in the phase space of the system (left), and its projection onto the 2-dimensional control plane (right)

Source: own study. 
a steep rise in the state variable as if it hops between lower and upper sheets. This corresponds to what happened in the real estate market in 2007, when the housing prices were rising by 10 per cent each month. Then the path in Figure 3 draws a curve along the bifurcation edge, which might eventually suggest the uncertainty as to its further behavior.

Presented results fully confirm the main hypothesis about the presence of the instability intervals during the evolution of the real estate market. Unlike smooth, long-term evolution onto the equilibrium surface, a short-term, catastrophic influence of the control parameters on the system might give rise to discontinuous (phase) transition, i.e. sharp change between different equilibrium states of the system without going through any equilibrium state in-between.

\section{Conclusions}

Mathematical models brought by the catastrophe theory might constitute a good description of empirical data from the real estate market under sudden price changes. Sudden price changes are internal and crucial characteristic of the real estate market in the sense that they are critical points on the system evolution path towards equilibrium state. Regardless of the parameters used in the fit procedure, obtained results suggest that neither linear nor logistic models are superior to the catastrophe model. Summarizing, the evolution path of the real estate market - under the influence of the control parameters - runs mostly over the areas of long-term stability, and only occasionally enters into the instability area.

\section{Notes}

1 Foryś (2011).

2 Adamczewski (2006); Czaja (1999).

3 Cellmer (2010).

4 Renigier-Biłozor (2010).

5 Wiśniewski (2007).

6 Batóg, Foryś (2010).

7 Trojanek (2008).

8 Fonseca et al. (2012); Kim, Yunjong (2012).

9 Thom (1976).

${ }^{10}$ Montagnana et al. (1989).

11 Cobb, Watson (1980).

${ }^{12}$ Grasman et al. (2009); R language and environment for statistical computing and graphics: www.r-project.org, cusp package: http://cran.r-project.org/web/packages/cusp/index.html.

${ }^{13}$ Foryśs (2011); Trojanek (2008); Żelazowski (2011). 
${ }^{14}$ Bełej, Kulesza (2011).

15 Jakimowicz (2003).

${ }^{16}$ Cobb (1998, April).

${ }^{17}$ Hartelman (1997).

\section{References}

Adamczewski, Z. (2006). Elementy modelowania matematycznego w wycenie nieruchomości. Warszawa: Oficyna Politechniki Warszawskiej.

Batóg, B. \& Foryś, I. (2010). Modele logitowe w analizie transakcji na warszawskim rynku mieszkaniowym. Studia i Materiaty TNN, Vol. 19 (2), 34-48.

Bełej, M. \& Kulesza, S. (2011). Modelowanie cen na rynku nieruchomości w warunkach nieciągłości. Wycena, Vol. 3 (96), 15-19.

Cellmer, R. (2010). Analiza przestrzenna dynamiki zmian cen nieruchomości lokalowych z wykorzystaniem regresji ważonej geograficznie. Acta Scientorum Polonorum Administratio Locorum. Vol. 9(3), 5-14.

Cobb, L. \& Watson, B. (1980). Statistical Catastrophe Theory: An Overview, Mathematical Modelling, Vol. 1 (4), 311-317.

Cobb, L. (1998, April). An Introduction to Cusp Surface Analysis, Technical report. Retrieved: June 20, 2012, from www.aetheling.com/models/cusp/Intro.html.

Czaja, J. (1999). Wymogi wyceny a statystyka. Rzeczoznawca Majątkowy, nr 2, Warszawa: PFSRM.

Fonseca, E.L., Ferreira, F.F., Muruganandum, P. \& Cedeira, H.A. (2012). Indentifying financial crises in real time, submitted to Physica A.

Foryś, I. (2011). Społeczno-gospodarcze determinanty rozwoju rynku mieszkaniowego w Polsce. Szczecin: Wydawnictwo Naukowe Uniwersytetu Szczecińskiego.

Grasman, R., van der Maas, H.L.J. \& Wagenmakers, E.-J. (2009). Fitting the cusp catastrophe in R: A cusp package primer. Journal of Statistical Software, Vol. 32, 1-27.

Hartelman, P.A.I. (1997). Stochastic Catastrophe Theory. Unpublished doctoral dissertation, University of Amsterdam, the Netherlands.

Jakimowicz, A. (2003). Od Keynesa do teorii chaosu. Warszawa: Wydawnictwo Naukowe PWN.

Kim, C.-J. \& Yunjong, E. (2012). Markov-switching models with evolving regime-specific parameters: Are post-war booms or recessions all alike. Discussion paper, private communication. 
Montagnana, M., Prizzon, F. \& Zorzi, F. (1989). Qualitative models for analyzing housing markets dynamics. Papers of the Regional Science Association, Vol. 69, 153-165.

Renigier-Biłozor, M. (2010). Analysis of real estate markets with the use of the rough set theory. Studia i Materiały TNN, Vol. 19 (1), 107-118.

Thom, R. (1976). Structural stability and morphogenesis: an outline of a general theory of models. Reading, Mass: Benjamin.

Trojanek, R. (2008). Wahania cen na rynku mieszkaniowym. Poznań: Wydawnictwo Akademii Ekonomicznej.

Wiśniewski, R. (2007). Wielowymiarowe prognozowanie wartości nieruchomości. Olsztyn: Wydawnictwo Uniwersytetu Warmińsko-Mazurskiego.

Żelazowski, K. (2011). Regionalne zróżnicowanie cen i ich determinant na rynku mieszkaniowym w Polsce. Studia i Materiaty TNN, Vol. 19 (3), 98-106. 